\title{
Arctic and Antarctic lakes as optical indicators of global change
}

\author{
Warwick F. Vincent, ${ }^{1 *}$ Isabelle Laurion, ${ }^{2}$ Reinhard Pienitz $^{2}$ \\ 'Antarctic CRC, Box 252-80, Hobart, Tasmania 7001, Australia \\ ${ }^{2}$ Centre d'Études Nordiques, Département de Biologie et Département de Géographie, Université Laval, Sainte-Foy, Québec G1K $7 P 4$, Canada
}

\begin{abstract}
Lakes are a major feature of Arctic and Antarctic landscapes and are likely to be sensitive indicators of climate change. New bio-optical technologies for in situ measurements (e.g. UV-profiling) and remote sensing (e.g. light detection and ranging) now offer a suite of options for long-term monitoring at these sites. Certain properties of high-latitude lakes are highly responsive to changes in climate forcing and could be targeted within a monitoring strategy based on optical properties; these include lake levels, lake-ice dynamics, phytoplankton biomass and chromophoric dissolved organic matter (CDOM). High-latitude lakes are optically sensitive to changes in CDOM export from their surrounding catchments that could result from climate effects on hydrology and vegetation. Using a new model based on biologically weighted transparency, we show that a $20 \%$ change in CDOM concentration (as measured by dissolved organic carbon) can have a much greater effect on UV inhibition of phytoplankton than a similar percentage change in stratospheric ozone. Much of this effect is due to UV-A, because the reduced photodamaging effect per unit energy (i.e. low biological weighting) in this waveband is offset by its higher incident flux at the lake surface relative to UV-B and its deeper penetration into the water column. These transparency calculations also show that small changes in CDOM in polar lakes will have a large effect on underwater light availability for photosynthesis. The spectral absorption and fluorescence properties of CDOM lend themselves to a variety of optical monitoring approaches. Future research on the paleooptics of CDOM will allow the interpretation of current optical trends in high-latitude lakes relative to the scales of natural variability in the past.
\end{abstract}

\section{INTRODUCTION}

Lakes are a prominent feature of the ice-free regions of Antarctica and are also a major element of high-latitude northern landscapes. They are the downstream integrators of a variety of catchment processes, and many of their ecosystem properties are responsive to small variations in annual heat budget. These features, in combination with the strong climate-change signals and stratospheric ozone depletion at high latitudes, suggest that polar lakes are highly appropriate sites for monitoring the effects of global change.

Recent advances in field instrumentation and remotesensing technologies have paved the way for a variety of novel approaches to the monitoring of lake ecosystems. In this paper we examine some of the approaches which may be of special relevance to monitoring environmental change in the North and South Polar regions. We focus particularly on those properties of the aquatic environment which can be measured using optical techniques. The technology in this area is evolving rapidly and lends itself to high-resolution

* Permanent address: Centre d'études nordiques et Département de biologie, Université Laval, Sainte-Foy, Québec G1K 7P4, Canada. observations over space and time, even at high-latitude sites where the logistics are often difficult and expensive.

Long-term monitoring programs based on optical variables should ideally focus on those properties of lakes that not only respond to climatic forcing but also integrate a variety of lake-plus-catchment processes. Such variables should be measurable by in situ techniques, by automated instrumentation and/or by remote sensing. It would be advantageous if such a record could also be extended into the past, for example via paleolimnological approaches, to allow current observations to be placed in their historical context and to define the scales of natural variability against which recent changes can be assessed.

In this paper we examine several features of high-latitude lake ecosystems that are likely to respond to changes in climate forcing and which could be incorporated within a monitoring strategy based on optical properties: lake levels, ice-cover dynamics, phytoplankton biomass and chromophoric dissolved organic matter (CDOM). We place special emphasis on CDOM because it plays a central role in several ecosystem processes and is dependent on catchment hydrology, vegetation and soils, and thus climate. It exerts an overriding control on underwater ultraviolet radiation (UVR) as well as photosynthetically active radiation (PAR) and provides a strong optical signature for long-term monitoring. Our results presented here show that high-latitude lakes have CDOM concentrations within a range where small vari- 
ations result in biologically significant shifts in underwater UV-A (UVR in the range $320-400 \mathrm{~nm}$ ) as well as UV-B $(280-320 \mathrm{~nm})$. Such effects contrast with those induced by stratospheric ozone depletion which are limited to changes in UV-B, a waveband that penetrates to much shallower depths than UV-A in natural waters.

\section{LAKE LEVELS}

One of the likely consequences of climate change is an alteration in the hydrological balance of lakes and their surrounding catchments. For example, a long-term warming trend in the boreal forest zone of Canada has been accompanied by reduced precipitation, decreased runoff and increased hydraulic residence time of the lakes of that region (Schindler and others, 1996). For glacier-fed endorheic lakes, including those at many high-latitude sites, changes in the radiation balance at the glacier face can lead to large shifts in the quantity of inflowing meltwater and thus variations in lake area, depth and volume. Chinn (1993) showed that lakes in the McMurdo Dry Valleys have consistently risen in water level throughout the 20th century, while measurements by Gibson and Burton (1996) at lakes in the Vestfold Hills (East Antarctica) indicated a more complex pattern, with rising water between 1978 and the mid-1980s, followed by dropping water levels. These latter authors noted that variations in water level in saline meromictic systems are accompanied by changes in the vertical structure of the water column which in turn can be used to infer past climates. Given the large differences in reflectance between land, water and ice, changes in lake level could be conveniently monitored by aerial photography or by satellite, in particular via the associated changes in lake area. Alternatively, depth could be determined directly via airborne LIDAR (light detection and ranging) observations which can be used to estimate, under ideal conditions, shallows up to about $40 \mathrm{~m}$ deep (Gauldie and others, 1996).

\section{LAKE-ICE DYNAMICS}

The dates of ice freeze-up and break-up, ice thickness and duration are all likely to be sensitive indicators of variations in climate. These variables will also have a wide-ranging influence on many physical and chemical properties of the aquatic ecosystem that directly or indirectly affect the biota, for example through changes in the length of the growing season, wind-induced mixing, gas transfer and underwater light availability. Walsh (1995) summarized the evidence for changing ice dynamics at a number of lake sites, and drew attention to the untapped potential of this approach to large-scale climate monitoring. Lake ice-cover thinning has been observed in continental Antarctica, suggestive of a warming trend, while measurements in the eastern Canadian Arctic show an increased frequency of multi-year lake ice (Doran and others, 1996) consistent with a cooling trend in this region.

Ice measurements can be made photographically (e.g. by automated cameras) or by sensors on aircraft or satellites (e.g. the advanced very high resolution radiometer). These optical approaches are likely to be superseded by satellite observations using synthetic aperture radar (SAR) based on active microwave sensing. SAR systems are continuing to improve in spatial resolution (30-100 $\mathrm{m}$ for RADARSAT) and they can be used to establish ice-cover extent even at night or under thick cloud cover (Massom, 1995). SAR data have been successfully applied to measure the duration of ice cover and other surface ice properties of lakes in the Yukon and northern Alaska (Morris and others, 1995) and in the subarctic region near Hudson Bay (unpublished data from C. R. Duguay and P. M. Lafleur).

\section{PHYTOPLANKTON}

The potential for major shifts in the distribution and productivity of plant communities has been of particular interest to terrestrial ecologists in their development of climatechange scenarios for high-latitude environments. Various indices of greenness have been applied to some high-latitude environments, most recently by Myneni and others (1997) who presented evidence of a 10 year consistent rise in the Normalized Difference Vegetation Index for latitudes higher than $45^{\circ} \mathrm{N}$. Climate change is also likely to result in changing nutrient export from catchments, changes in the hydraulic residence time of lakes, and variations in lakewater mixing regimes, all of which may influence the species composition and biomass of lake phytoplankton.

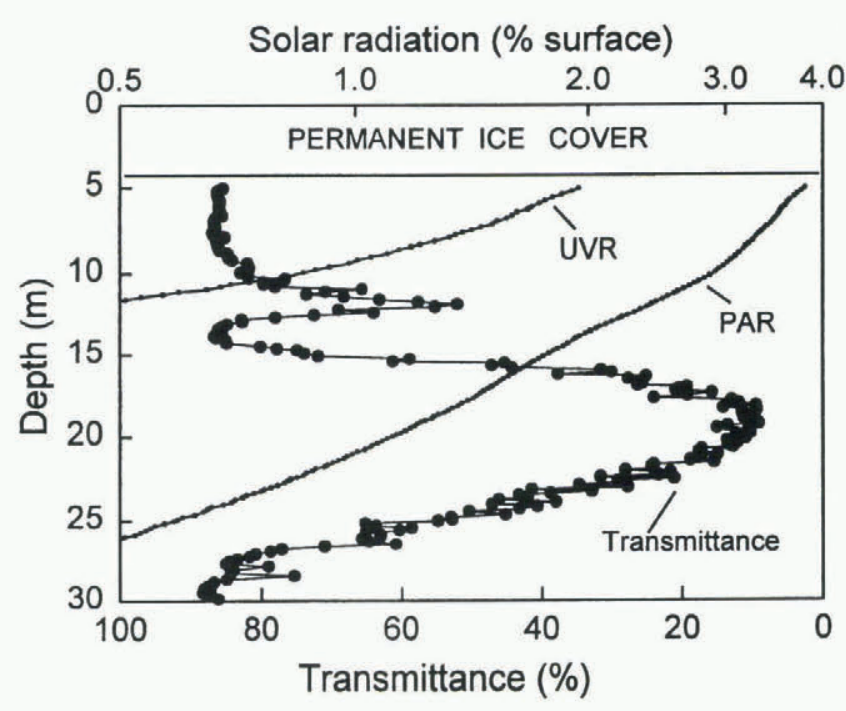

Fig. 1. Bio-optical profiles for the east lobe of Lake Bonney, McMurdo Dry Valleys, Antarctica, 14 December 1995 $(1215 \mathrm{~h})$ : downwelling radiation at $320 \mathrm{~nm}$ (UVR), downwelling photosynthetically active radiation (PAR) and transmittance at $660 \mathrm{~nm}$ (note the scale reversal to show the upper and lower pigment maxima). Measurements were made with a Biospherical PUV-500 profiling radiometer fitted with a Seatech $10 \mathrm{~cm}$ transmissometer.

A broad range of optical technologies is now available for rapid in situ measurements of phytoplankton distribution and abundance. High-resolution measurements of particle distribution can be made by fluorometry or transmissometry which allow subsurface pigment maxima to be accurately located and quantified (Fig. 1). Techniques such as solar-induced fluorescence can provide information about the photosynthetic activity of phytoplankton as a function of depth in the water column (e.g. Garcia-Mendoza and Maske, 1996), and have been applied to lakes in both the North and South Polar zones (Vincent and others, in press). 
A variety of remote-sensing options are available for phytoplankton measurements, and the advent of new satellite observation systems with high spatial resolution, such as MERIS and MODIS with resolution of $250-300 \mathrm{~m}$ (Massom, 1995), is of 'special interest to limnologists. Recent advances in laser fluorosensors indicate that LIDAR has considerable potential for airborne measurements of Chl $a$ in the surface waters of lakes and coastal environments (Nieke and others, 1997b). There is a great variety of paleolimnological techniques based on the measurement of fossil algal remains in lake sediments (Charles and others, 1994 and references therein), and these approaches will continue to provide new insights into the long-term variability of high-latitude lakes (e.g. Pienitz and Smol, 1993).

\section{CDOM}

Climate-related changes in the hydrology and vegetation ecology of catchments are likely to have a strong effect on the export of dissolved organic compounds into receiving streams and lake waters. There is increasing evidence that such compounds exert a major influence on many properties of lake ecosystems, including radiative transfer (Laurion and others, 1997), mixing regimes (Fee and others, 1996) and microbial carbon dynamics (Wetzel, 1995). In the Experimental Lakes Area a decrease in runoff and increased hydraulic residence time were accompanied by a $15-20 \%$ decrease in dissolved organic carbon (DOC) over 20 years (Schindler and others, 1996). The coloured fraction of the dissolved organics, referred to as CDOM, largely controls the spectral penetration of UVR and, to a lesser extent, photosynthetically available radiation (PAR). In this section we evaluate the magnitude of these effects in high-latitude lakes, and the potential for monitoring coupled lakecatchment systems via the optical changes induced by variations in CDOM.

\section{CDOM effects on underwater UVR}

UVR penetrates deeply in high-latitude lakes as a result of the low concentration and low UVR-absorbing characteristics of CDOM in these waters (Laurion and others, 1997). Measurements of underwater spectral irradiance along latitudinal transects in northern North America show a major increase in the UV transparency of lakes across the transitional forest-tundra region of the sub-Arctic, and a further abrupt increase across the transition from tundra to polar desert (Vincent and Pienitz, 1996; Pienitz and others, 1997a, b; Vincent, in press). These changes are associated with the trend of decreasing concentration of CDOM with increasing latitude. Antarctic lakes are similarly characterized by low CDOM and the deep penetration of UVR (Fig. 1). High-latitude lakes are therefore little protected from the effects of stratospheric ozone depletion and rising UV-B, which are proceeding most rapidly in the polar regions.

Our previous measurements of UVR in Arctic, sub-Arctic and Antarctic lakes have been made with a profiling radiometer (model PUV-500 from Biospherical Instrument Inc.) that measures downwelling UVR at 305, 320, 340 and $380 \mathrm{~nm}$. From these measurements a set of empirical relationships was derived for attenuation length or "transparency" $(T(\lambda),=1 / K$ where $K$ is the diffuse attenuation coefficient) as a function of DOC concentration (Table 1). The striking goodness-of-fit of this $\log$ - log model (Fig. 2)
Table 1. Empirically derived relationships between attenuation length $(1 / K)$ and DOC concentration for Arctic, subArctic and Antarctic lakes

\begin{tabular}{lcccc}
\hline Wavelength & $c$ & $m$ & $n$ & $r^{2}$ \\
\hline $305 \mathrm{~nm}$ & 0.12 & -1.68 & 7 & 0.93 \\
$320 \mathrm{~nm}$ & 0.42 & -1.98 & 20 & 0.95 \\
$340 \mathrm{~nm}$ & 0.58 & -2.04 & 20 & 0.95 \\
$380 \mathrm{~nm}$ & 0.75 & -1.91 & 20 & 0.94 \\
PAR & 0.99 & -1.11 & 20 & 0.90 \\
\hline
\end{tabular}

Note: Coefficients are for the equation $\log (1 / K)=c+m \log$ [DOC]; $n=$ number of lakes sampled. DOC was measured with a Shimadzu TOC Analyser. An illustrative scatter plot is given in Figure 2 (further details in Vincent and others, in press).

may in part reflect the lack of bio-optical diversity amongst the sampled lakes; all are oligotrophic, non-turbid systems in which seston (biotic and abiotic suspensoids) plays only a minor role in light absorption and scattering.

We can extend these empirical transparency models by considering the penetration of UVR weighted for its biological effectiveness and for the changes in incident spectral radiation that result from ozone depletion. A parameter $T^{*}(\lambda)$, the "weighted transparency" at each wavelength, may be defined as:

$$
T^{*}(\lambda)=(1 / K) \epsilon E_{0 \mathrm{rel}} F
$$

where $K$ is the diffuse attenuation coefficient at that wavelength $(\lambda), \epsilon$ is the biological weighting function which expresses the damaging effect of radiation at that wavelength on a relative scale $(\epsilon=1.0$ at $300 \mathrm{~nm}), E_{0 \mathrm{rel}}$ is the surface irradiance at that wavelength, also on a relative scale $\left(E_{0 \mathrm{rel}}=1.0\right.$ at $\left.400 \mathrm{~nm}\right)$, and $F$ is the factor of enhancement in surface radiation flux at the wavelength for a given stratospheric ozone depletion. This weighted transparency

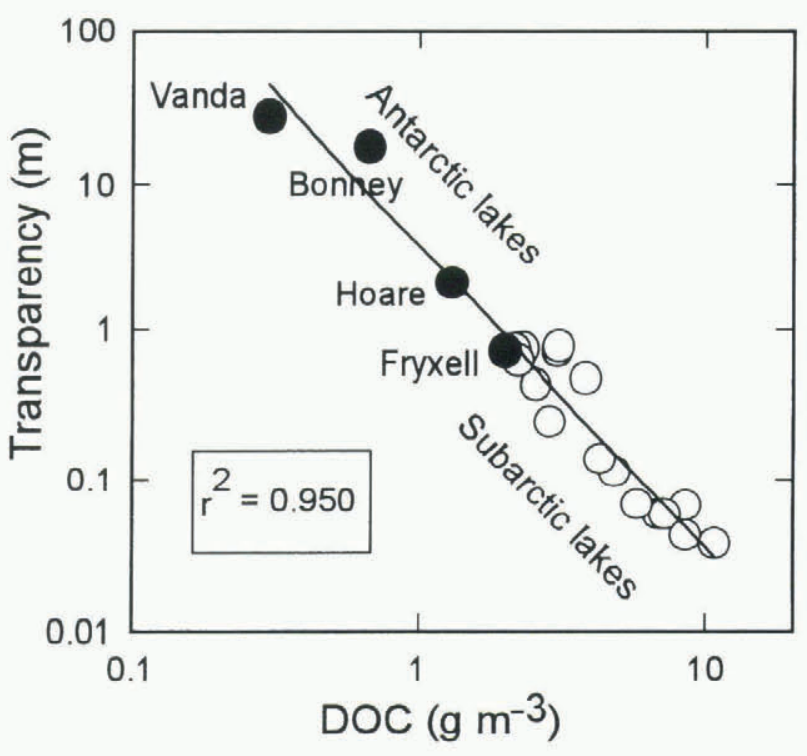

Fig. 2. Relationship between UVR transparency $(1 / K(\lambda)$, here illustrated by $\lambda=340 \mathrm{~nm}$ ) and $D O C$ concentration for Antarctic lakes (solid circles) and sub-Arctic lakes (open circles). 
Table 2. Effect of ozone depletion vs CDOM reduction on the weighted transparency $\left(10^{-3} \mathrm{~m}\right)$ of a water column to UVR

UVR wavelength

$30.5 \mathrm{~nm} \quad 320 \mathrm{~nm} \quad 340 \mathrm{~nm}$

$380 \mathrm{~nm}$

Total

$\begin{array}{ll}2 \mathrm{mg} \mathrm{DOCl}{ }^{-1} & 20.4 \\ \text { Ozone depletion } & 48.6(138 \%) \\ \text { CDOM reduction } & 29.6(45 \%) \\ & \\ 1 \mathrm{mg} \mathrm{DOCl}^{-1} & 65.1 \\ \text { Ozone depletion }_{\text {CDOM reduction }} & 155(138 \%) \\ & 153(135 \%)\end{array}$

15.2
$17.9(18 \%)$
$23.6(48 \%)$
59.9
$70.7(18 \%)$
$165(175 \%)$

19.8
$19.8(0 \%)$
$31.2(57 \%)$
81.3
$81.3(0 \%)$
$230(183 \%)$

10.5

$10.5(0 \%)$

$16.1(53 \%)$

39.6

$39.6(0 \%)$

$105(165 \%)$
14.3

$17.7(24 \%)$

$22.0(54 \%)$

54.6

$65.7(20 \%)$

$147(169 \%)$

Note: The values at each wavelength are for $T^{*}(\lambda)$ as in Equation (1), or $T_{\mathrm{UVR}}^{*}$, the mean values for the UVR waveband as approximated in Equation (3). Ozone depletion refers to a $20.6 \%$ decrease in total column ozone (from 310 to $250 \mathrm{DU}$, as in Frederick and Snell (1988)); CDOM reduction refers to a $0.4 \mathrm{mg}$ DOC $1^{-1}$ decrease from initial conditions $\left(2 \mathrm{or} 1 \mathrm{mg} \mathrm{DOCl}^{-1}\right)$. The percentage increase in weighted transparency relative to initial conditions is given in parentheses.

index can be averaged across a series of wavelengths to produce a mean value for a particular waveband:

$$
T_{\mathrm{av}}^{*}=\frac{1}{\Delta \lambda} \int_{\lambda}^{\lambda+\Delta \lambda} T^{*}(\lambda) \mathrm{d} \lambda .
$$

$T_{\text {av }}^{*}$ for the UVR waveband can be approximated in terms of $T^{*}(\lambda)$ values for each of the four measured wavelengths:

$$
\begin{aligned}
T_{\mathrm{UVR}}^{*} \approx & 0.1 T^{*}(305 \mathrm{~nm})+0.2 T^{*}(320 \mathrm{~nm}) \\
& +0.2 T^{*}(340 \mathrm{~nm})+0.5 T^{*}(380 \mathrm{~nm})
\end{aligned}
$$

where the coefficients in this equation are for rectangular integration across the UVR range.

Table 2 presents the results of a series of calculations based on Equations (1) and (3) and the bio-optical relationships for high-latitude waters given in Table 1. For these calculations we used $\epsilon$ values based on Cullen and others (1992). These were derived for UVR photo-inhibition of photosynthesis of marine diatoms, but they have also provided reasonable biological weightings for UVR inhibition of growth by Antarctic cyanobacteria (Quesada and Vincent, 1997). $E_{0 \text { rel }}$ values were obtained for an incident solar radiation curve (Milot-Roy and Vincent, 1994, fig. 7), and $F$ values were derived from Frederick and Snell (1988, fig. 2B) for a total column ozone thickness of 310 and 250 Dobson Units (DU).

Relative to the initial conditions of $2 \mathrm{mg} \mathrm{DOCl}^{-1}$ and $310 \mathrm{DU}$, a $20.6 \%$ reduction in ozone results in a $>100 \%$ increase in $T^{*}(\lambda)$ at short UVR wavelengths, but no change in long-wavelength UVR (Table 2). By contrast, a 20\% decrease in DOC from 2 to $1.6 \mathrm{mg} \mathrm{Cl}^{-1}$ results in a large $(>40 \%)$ increase in $T^{*}(\lambda)$ at all UVR wavelengths, and the relative increase in total waveband $T_{\mathrm{UVR}}^{*}$ is twice that induced by the ozone depletion. These effects are more striking at lower DOC concentrations. For example, the same absolute change in DOC, but from 1 to $0.6 \mathrm{mgl}^{-1}$, results in a $>130 \%$ increase in $\mathrm{T}^{*}(\lambda)$ at all UVR wavelengths; $T_{\mathrm{UVR}}^{*}$ increases by $169 \%$, an effect some 8 times greater than that caused by $60 \mathrm{DU}$ of ozone depletion (Table 2).

This analysis of weighted UVR penetration into natural waters illustrates the pivotal role played by CDOM and is consistent with earlier suggestions by Schindler and others (1996) and Williamson and others (1996) of the importance of such effects relative to changes in incident UVR. Our results show that in the low-CDOM regime which characterizes high-latitude lakes, changes in the concentration of DOC can have a greater effect on biologically weighted un- derwater UVR than the equivalent percentage change in stratospheric ozone. Much of this effect is due to UV-A, because the reduced photodamaging effect per unit energy (i.e. low $\epsilon$ ) in this waveband is offset by its deeper penetration and higher incident flux at the lake surface relative to UV-B.

\section{CDOM effects on underwater PAR and UVR/PAR}

Although CDOM absorbance of solar radiation is especially strong in the UVR region of the spectrum, there is also some absorbance in the PAR range. Our measurements in high-latitude northern lakes indicate that CDOM can account for a large percentage of the total photon budget for PAR and that climate-related shifts in DOC export to lakes could also influence the availability of underwater light for photosynthesis (unpublished data from S. Markager and W. F. Vincent). Arrigo and Brown (1996) modelled the combined effects of CDOM on UVR screening and PAR removal in the sea, and concluded that the latter can eliminate or exceed the positive effects of the former. For a decrease in CDOM from 2.0 to $1.6 \mathrm{mg} \mathrm{DOC}^{-1}$, as above, we calculate that the transparency of the water column to PAR would increase by only $11 \%$, but a shift from 1 to $0.6 \mathrm{mg} \mathrm{l}^{-1}$ would increase transparency (e.g. the depth of the 1\% PAR level) by $76 \%$.

UVR impairment of biological systems is likely to represent the net balance between photochemical damage and biosynthetic repair. The latter is determined in part by the UVR flux, while biosynthesis in phototrophic organisms may depend on PAR availability. The spectral ratio of UVR to PAR may therefore be a more meaningful index of damage potential than UVR alone. Studies on high-latitude lakes in the northern circumpolar region (Vincent and Pienitz, 1996; Laurion and others, 1997) as well as Antarctica (Vincent and others, in press) have shown these waters lie within a CDOM concentration range where this ratio rises sharply with decreasing DOC. For the two CDOM scenarios and the empirical relationships given in Table 1 , the UVR $(320 \mathrm{~nm}) / \mathrm{PAR}$ ratio would rise by $22 \%$ for the shift from 2 to $1.6 \mathrm{mg} \mathrm{DOCl}^{-1}$, and by $56 \%$ for the shift from 1 to $0.6 \mathrm{mg} \mathrm{DOCl}^{-1}$.

\section{Optical monitoring of CDOM}

The preceding subsections have emphasized how CDOM controls the underwater light field in high-latitude lakes. It follows that certain optical properties of these lakes can be 
used as sensitive proxies for CDOM, for example attenuation lengths derived from in situ UVR profiles (Fig. 1; Table 1). For remote-sensing applications, attention has especially focused on the spectral fluorescence properties of CDOM, in particular its emission maximum normalized to the Raman scattering peak for water (Green and Blough, 1995; Nieke and others, 1997a). Figure 3 shows the emission spectra for two lakes at opposite ends of the CDOM continuum for high-latitude waters: Lake Bonney (Antarctica) in which CDOM emission is small relative to the Raman peak $\left(\right.$ DOC $\left.=0.7 \mathrm{mg} \mathrm{l}^{-1}\right)$, and a sub-Arctic lake characterized by much higher concentrations of CDOM $\left(8 \mathrm{mg} \mathrm{DOC}^{-1}\right)$ in which the Raman peak is a small contribution to total fluorescence. Emission signals of this type from surface waters can be detected and quantified by active remote-sensing techniques such as LIDAR (Vodacek and others, 1995; Nieke and others, 1997a). CDOM can be incorporated into the ice of northern lakes during freeze-up (R. Pienitz and W. F. Vincent, unpublished observations) and the organic content of lake ice might also be monitored in this way, although such measurements would be obstructed by any overlying snow.

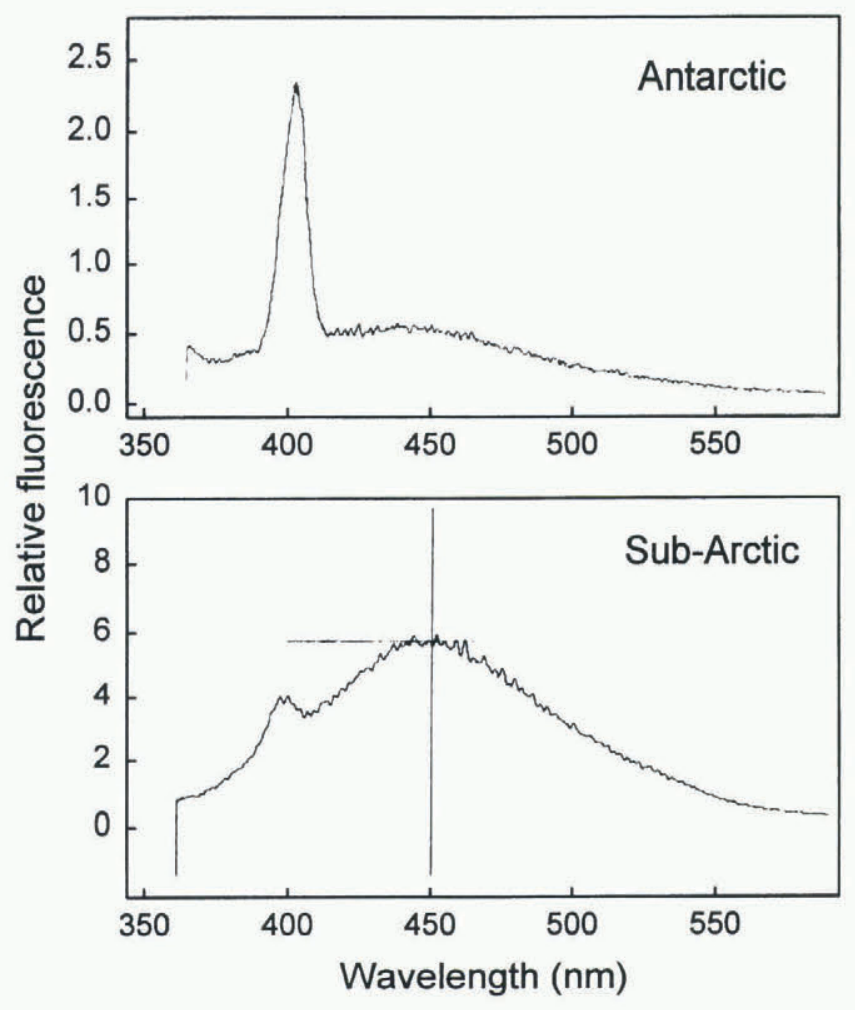

Fig. 3. Fluorescence emission spectra for $0.22 \mu \mathrm{m}$ filtered water from an Antarctic lake (Lake Bonney) and a sub-Arctic lake (near Lac à l'eau claire, northern Québec). Excitation was at $348 \mathrm{~nm}$, and measurements were obtained with a Shimadzu spectrofluorometer model RF5000.

Recent advances in paleolimnology have led to the development of new analytical and statistical techniques for reconstructing past lake environments (Charles and others, 1994). These approaches are of special interest for high-latitude lakes, where there is a paucity of historical data but a potentially interesting record of variations because of their high sensitivity to natural as well as human perturbation. Pienitz and Smol (1993) have shown that dissolved organic carbon levels in Canadian lakes can be successfully hindcast from the multivariate analysis of diatom microfossils contained within their sediments. In combination with the biooptical models now available for high-latitude lakes (Table 1), this leads to the exciting prospect of reconstructing past underwater light regimes and the extension of records for optical variables such as $T^{*}$ into the past. This new theme in paleolimnology, "lake paleo-optics" (Vincent and Pienitz, 1996), offers opportunities for integrating studies from the present-day optical monitoring of lakes, as proposed above, with knowledge of their historical variations in underwater light regime.

\section{ACKNOWLEDGEMENTS}

This work was supported by grants from the Fonds pour la Formation de Chercheurs et l'Aide à la Recherche (FCAR, Québec) and the Natural Sciences and Engineering Research Council (NSERC, Canada). Logistic support was provided by the United States Antarctic Research Program, Centre d'etudes nordiques and Polar Continental Shelf Project (this is publication No. PCSP/ÉPCP 01897). We thank K. Michael, J. C. Ellis-Evans and J. A. E. Gibson for their helpful review comments.

\section{REFERENCES}

Arrigo, K. R. and C.W. Brown. 1996. Impact of chromophoric dissolved organic matter on UV inhibition of primary productivity in the sea. Mar. Ecol. Prog. Ser, 140 (1-3), 207-216.

Charles, D. F., J. P. Smol and D. R. Engstrom. 1994. Paleolimnological approaches to biological monitoring. In Loeb, S. L. and A. Spacie, eds. Biological monitoring of aquatic systems. Boca Raton, FL, CRC Press, 233-293.

Chinn, T. J. 1993. Physical hydrology of the Dry Valley lakes. In Green, W. J. and E. I. Friedmann, eds. Physical and biogeochemical processes in Antarctic lakes. Washington, DC, American Geophysical Union, 1-5l. (Antarctic Research Series 59.

Cullen, J.J., P. J. Neale and M. P. Lesser. 1992. Biological weighting function for the inhibition of phytoplankton photosynthesis by ultraviolet radiation. Science, 258 (5082), 646-650.

Doran, P.T., C. P. McKay, W. P. Adams, M. C. English, R. A. Wharton, Jr and M. A. Meyer. 1996. Climate forcing and thermal feedback of residual lake-ice covers in the high Arctic. Limnol. Oceanogr., 41 (5), 839-848.

Fee, E. J., R. E. Hecky, S. E. Kasian and D. R. Cruikshank. 1996. Effects of lake size, water clarity and climatic variability on mixing depths in Canadian Shield lakes. Limnol. Oceanogr., 41 (5), 912-920.

Frederick, J. E. and H. E. Snell. 1988. Ultraviolet radiation levels during the Antarctic spring. Science, 241 (4864), 438-440.

Garcia-Mendoza, E. and H. Maske. 1996. The relationship of solar-stimulated natural fluorescence and primary productivity in Mexican Pacific waters. Limnol. Oceanogr., 41 (8), 1697-1710.

Gauldie, R.W., S. K. Sharma and C. E. Helsley. 1996. LIDAR application to fisheries monitoring and problems. Can. 7. Fish. Aquat. Sci., 53(6), 1459-1468.

Gibson, J. A. E. and H. R. Burton. 1996. Meromictic lakes as recorders of climate change: the structures of Ace and Organic Lakes, Vestfold Hills, Antarctica. Proceedings of the Royal Society of Tasmania, 130 (2), 73-78.

Green, S. A. and N.V. Blough. 1994. Optical absorption and fluorescence properties of chromophoric dissolved organic matter in natural waters. Limnol. Oceanogr., 39(8), 1903-1916.

Laurion, I., W. F. Vincent and D. R. S. Lean. 1997. Underwater ultraviolet radiation: development of spectral models for northern high latitude lakes. Photochem. Photobiol., 65 (1), 107-114.

Massom, R. 1995. Satellite remote sensing of polar snow and ice: present status and future directions. Polar Rec., 31 (177), 99-114.

Milot-Roy, V. and W. F. Vincent. 1994. UV radiation effects on photosynthesis: the importance of near-surface thermoclines in a subarctic lake. In Williamson, C. E. and H. E. Zagarese, eds. Ir pact of $U V-B$ radiation on pelagic freshwater ecosystems. Stuttgart, E. Schweizerbart'sche Verlagsbuchhandlung, 171-184. (Advances in Limnology 43.)

Morris, K., M. O. Jeffries and W. F. Weeks. 1995. Ice processes and growth history on Arctic and sub-Arctic lakes using ERS-1 SAR data. Pol. Rec., $31(177), 115-128$.

Myneni, R. B., C. D. Keeling, C. J. Tucker, G. Asrar and R. R. Nemani. 1997. Increased plant growth in the northern high latitudes from 1981 to 1991. 
Nature, 386(6626), 698-702.

Nieke, B., R. Reuter, R. Heuermann, H. Wang, M. Babin and J.-C. Therriault. 1997a. Light absorption and fluorescence properties of chromophoric dissolved organic matter (CDOM) in the St. Lawrence Estuary (Case 2 waters). Continental Shelf Res., 17 (3), 235-252.

Nieke, B., W. F. Vincent, J. -C. Therriault, L. Legendre, J. -F. Berthon and A. Condal. 1997b. Use of a shipborne laser fluorosensor for remote sensing of chlorophyll $a$ in a coastal environment. Remote Sensing Environ., 60 (2), $140-152$.

Pienitz, R. and J. P. Smol. 1993. Diatom assemblages and their relationship to environmental variables in lakes from the boreal forest-tundra ecotone near Yellowknife, Northwest Territories, Canada. Hydrobiologia, 269-270, 391-404.

Pienitz, R., J. P. Smol and D. R. S. Lean. 1997a. Physical and chemical limnology of 24 lakes located between the Yellowknife and Contwoyto Lake, Northwest Territories (Canada). Can. J. Fish. Aquat. Sci., 54(2), 347-358.

Pienitz, R., J. P. Smol and D. R. S. Lean. 1997b. Physical and chemical limnology of 59 lakes located between the southern Yukon and the Tuktoyaktuk Peninsula, Northwest Territories (Canada). Can. J. Fish. Aquat. Sci., 54(2), 330-346.

Quesada, A. and W. F. Vincent. 1997. Strategies of adaptation by Antarctic cyanobacteria to UV radiation. European f. Phycol., 32(4), 335-342.

Schindler, D. W., P. J. Curtis, B. R. Parker and M. P. Stainton. 1996. Conse- quences of climate warming and lake acidification for UV-B penetration in North American boreal lakes. Nature, 379 (6567), 705-708.

Vincent, W. F. In press. Polar desert ecosystems in a changing environment: a north south perspective. In Lyons, E. B., I. Hawes and C. HowardWilliams, eds. Antarctic desert ecosystems. Rotterdam, A. A. Balkema.

Vincent, W. F. and R. Pienitz. 1996. Sensitivity of high latitude freshwater ecosystems to global change: temperature and solar ultraviolet radiation. Geosci. Can., 23(4), 231-236.

Vincent, W. F., R. Rae, I. Laurion, C. Howard-Williams and J. C. Priscu. In press. Transparency of Antarctic lakes to ultraviolet radiation. Limnol. Oceanogr.

Vodacek, A., F. E. Hoge, R. N. Swift, R. N. Yungel and N.V. Blough. 1995. The use of in situ and airborne fluorescence measurements to determine UV absorption coefficients and DOC concentrations in surface waters. Limnol. Oceanogr., $\mathbf{4 0}(2), 411-415$.

Walsh, J. E. 1995. Long-term observations for monitoring of the cryosphere. Climatic Change, 31 (2-4), 369-394.

Wetzel, R. G. 1995. Death, detritus and energy flow in aquatic ecosystems. Freshwater Biol., 33(1), 83-89.

Williamson, C. E., R. S. Stemberger, D. P. Morris, T. M. Frost and S. G. Paulsen. 1996. Ultraviolet radiation in North American lakes: attenuation estimates from DOC measurements and implications for plankton communities. Limnol. Oceanogr., 41 (5), 1024-1034. 